\title{
Prediction of Electromagnetic Forces and Vibrations in SRMs Operating at Steady-State and Transient Speeds
}

\author{
Zhangjun Tang, Senior Member, IEEE, Pragasen Pillay, Fellow, IEEE, Yicheng Chen, and \\ Avoki M. Omekanda, Senior Member, IEEE
}

\begin{abstract}
Although some research has been conducted on vibrations in switched reluctance motors (SRMs), the response during transients, which may occur during sudden load changes or braking, has not received much investigation. In this paper, a simulation model to predict the transient vibration of SRMs is developed. The vibration prediction model is built based on the detailed normal force versus phase current and rotor position lookup table using finite-element calculations. The model is then verified by a running motor test, which shows acceptable accuracy. The results reveal that there are abundant harmonics of transient force during transients and, thus, resonance may be excited. This model allows the possibility of improved design of SRMs from a vibration and acoustic noise point of view.
\end{abstract}

Index Terms-Electromagnetic force, finite-element calculation, normal force, switched reluctance motor (SRM), transient, vibration, vibration simulation.

\section{INTRODUCTION}

$\mathbf{T}$ HE subject of vibrations in switched reluctance motors (SRMs) has attracted recent attention, including vibration tests [1], [2], modal analysis [3], and resonant frequency calculations [4]. However, the transient vibration during startup, braking, and sudden load change remains unknown. In some circumstances, the transient vibration is more important than the steady state value, because the switched reluctance motors (SRMs) is running in the transient state most of the time, for example with the application of the SRM as a braking motor in automobiles.

It is now well known that the normal force between SRM stator poles and rotor poles causes an attraction and, thus, an ovalization of the stator, which is the main cause of SRM vibration and acoustic noise [1]. The normal force in the SRM is very difficult to measure from experiment, and cannot be easily and

Paper IPCSD-05-014, presented at the 2004 Industry Applications Society Annual Meeting, Seattle, WA, October 3-7, and approved for publication in the IEEE TRANSACTIONS ON INDUSTRY APPLICATIONS by the Electric Machines Committee of the IEEE Industry Applications Society. Manuscript submitted for review August 20, 2004 and released for publication March 28, 2005.

Z. Tang is with Stryker Instruments, Kalamazoo, MI 49001 USA (e-mail: zhangjun.tang@gmail.com).

P. Pillay is with the Department of Electrical and Computer Engineering, Clarkson University, Potsdam, NY 13699 USA (e-mail: pillayp@ clarkson.edu).

Y. Chen is with Siemens Energy and Automation, Inc., Alpharetta, GA 30005 USA (e-mail: yicheng.chen@ siemens.com).

A. M. Omekanda is with Delphi Research Labs, Shelby Township, MI 48306 USA (e-mail: avoki.omekanda@ delphi.com).

Digital Object Identifier 10.1109/TIA.2005.851032 accurately modeled analytically, because of the double saliency of the stator and rotor poles, as well as the highly saturated nature of the flux density.

The normal forces, which excites vibrations in SRMs, depends largely on the transient current. The simulation of the SRM phase current is found in several papers [5]-[7]. PSpice and Matlab/SIMULINK have been used, with acceptable results. Both linear and nonlinear models have been used in those papers. The phase current waveforms after reaching steady state as well as during startup were shown. However, the operation during sudden load changes or braking has not been investigated.

In this paper, the simulation of transient vibrations during different operating conditions, such as startup, sudden load change, and braking, is developed. The vibration prediction model is based on the detailed normal force versus phase current and rotor position lookup table using finite-element calculations. To verify the simulation results, the running motor test is driven by a classic converter controlled by dSPACE, which has the functions of a digital signal processor (DSP) and AD/DA converter, and can be run in a Matlab/Simulink environment. An 8/6-pole 4-kW SRM is used for experimental validation of the simulation results. Both phase current and stator vibration are measured, with acceptable accuracy.

\section{Numerical CAlCUlation of Normal Force AND LOOKUP TABLE CONSTRUCTION}

Because of the structural complexity of SRMs and highly saturated nature of the flux density, it is very difficult to accurately model the normal force analytically. Thus, a two-dimensional (2-D) nonlinear finite-element model (FEM) in ANSYS is used, for the electromagnetic force analysis. A 4-kW 8/6-pole SRM with four phases is used in this research. Fig. 1 shows the meshing of the elements for the model. Fig. 2 has the fluxlinkage plot of the motor.

Static force calculations are carried out for 31 angles from the aligned to unaligned position and 25 different currents from 1 to $25 \mathrm{~A}$. Fig. 3 shows the force plot of the SRM. It is clear that the normal force dominates the tangential force, and the force concentrates on the stator pole-rotor pole area. Fig. 4 is the plot of the normal force versus phase current and rotor position.

This normal force versus phase current and rotor position lookup table can now be used to obtain the actual normal force acting on the stator for an arbitrary phase current waveform, as 


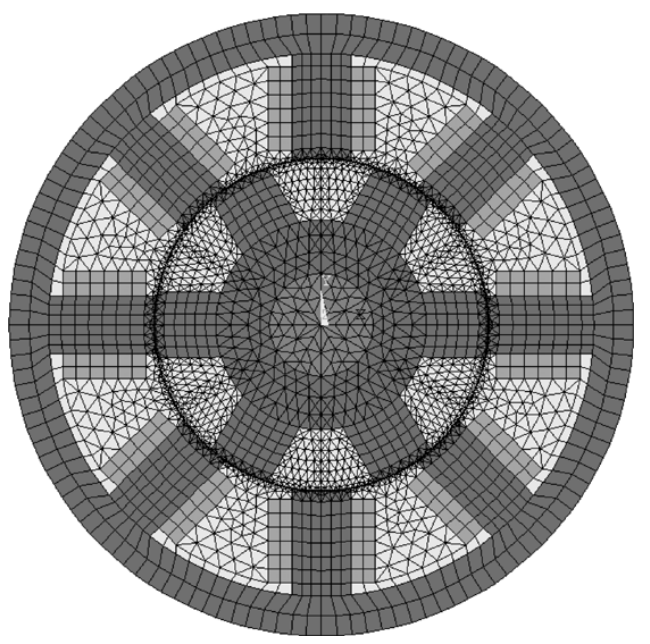

Fig. 1. Finite-element meshing for electromagnetic analysis.

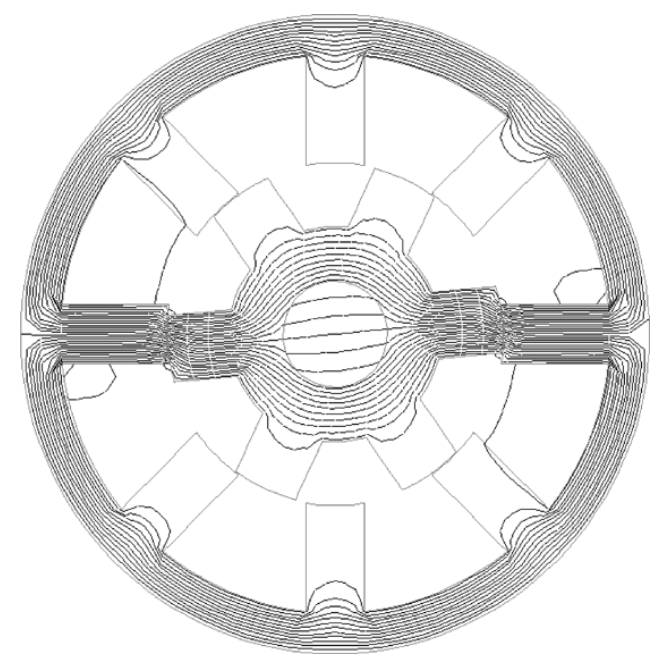

Fig. 2. Flux linkage plot.

long as the current waveform is known. It will be used to determine the transient forces and force harmonics, and hence to calculate the vibration resulting from the normal forces.

\section{Modeling AND Simulation of TRAnSiEnt CuRRENTS}

\section{A. SRM Dynamics}

The operation and modeling of SRMs is entirely different from conventional motors. The complication in modeling is due to the highly nonlinear nature of the motor. There have been many attempts to model SRMs [5]-[7], which basically differ in variables chosen for solution, therefore requiring different data sets. It is convenient to choose the governing equations as follows.

The electromagnetic equation is

$$
\frac{d \Psi}{d t}=v-R i
$$

where $\psi$ is the flux linkage in the phase winding, $\mathrm{v}$ is the terminal voltage, $i$ and $R$ are phase current and phase winding resistance, respectively.

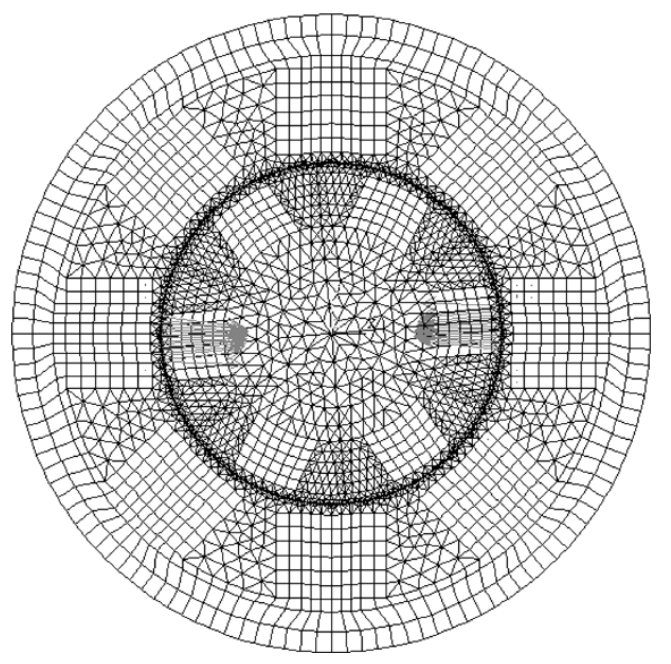

Fig. 3. Force plot.

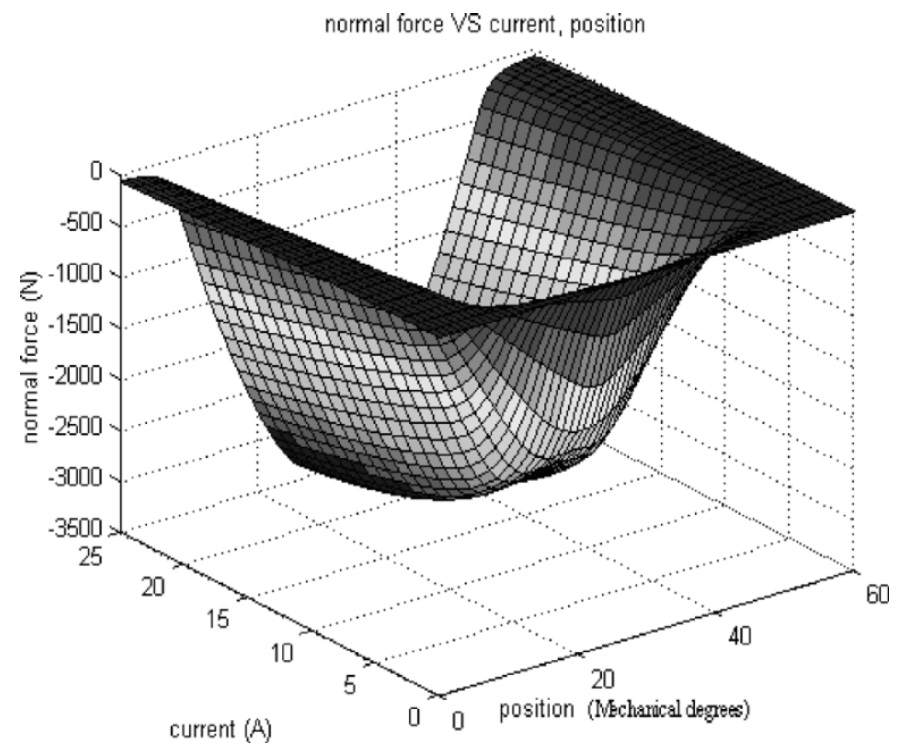

Fig. 4. Normal force versus phase current and rotor position.

The mechanical equation is

$$
\begin{aligned}
T & =T_{1}+k_{\omega} \omega+J \frac{d \omega}{d t} \\
\omega & =\frac{d \theta}{d t}
\end{aligned}
$$

where $T$ is the electromagnetic torque, $T_{l}$ is the load torque, $k_{\omega}$ is the friction damping coefficient, $J$ is the moment of inertia of the rotor, and $\omega$ is the rotor speed.

It is obvious that the above equations have no analytical solution as the flux linkage is a nonlinear function of current and rotor angle, hence, numerical analysis is necessary.

\section{B. Simulation of Currents}

Instead of using a linear model of the SRM, two lookup tables are used in this simulation. One is flux linkage versus rotor position and phase current; the other is phase current and rotor position versus torque. The simulation model is shown in Fig. 5, with Fig. 5(a) being the entire model, and Fig. 5(b) being the 


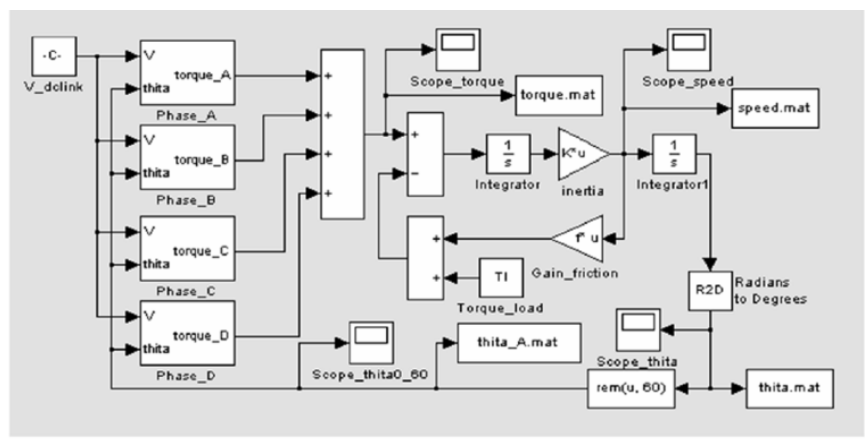

(a) Entire Model

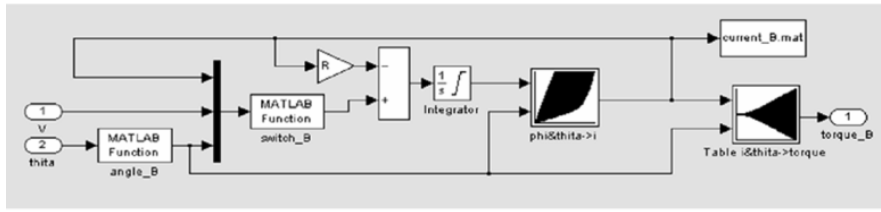

(b) Simulation Block for One Phase

Fig. 5. Simulation model for SRM-lookup table method.

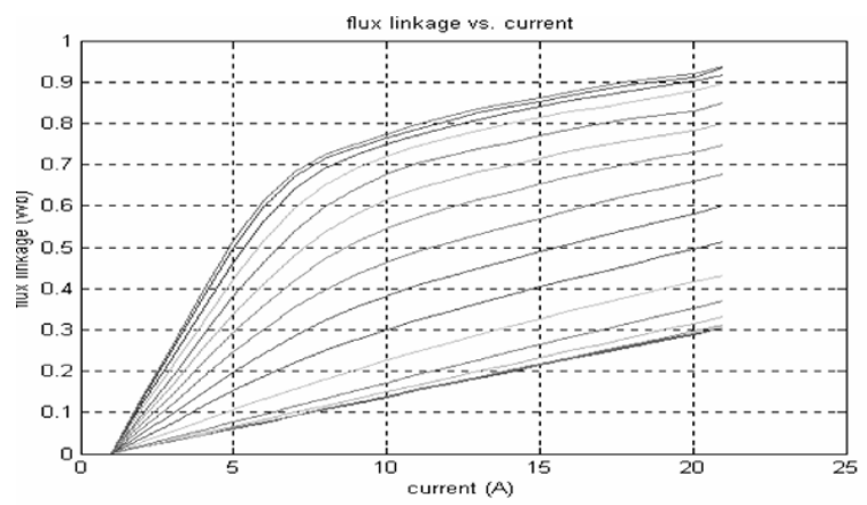

(a) Flux-linkage vs. Current at Different Rotor Positions

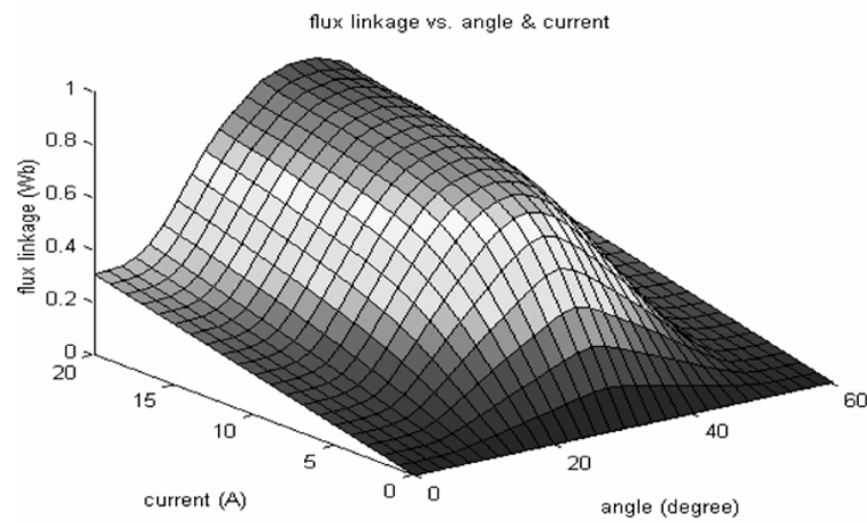

(b) 3-D View of Flux-linkage vs. Current \& Rotor Position

Fig. 6. Flux linkage versus phase current and rotor position.

subsystem for each phase, which includes two lookup tables and is used to calculate the electromagnetic torque.

The data for the first lookup table can be obtained from FEM calculations (if the motor is in the design stage), or from experimental test results (if the prototype exists). In this paper the data are measured from experimental tests. Fig. 6 shows the flux linkage versus phase current and rotor position.

The torque versus rotor position and phase current lookup table can also be obtained from FEM calculations or experi-

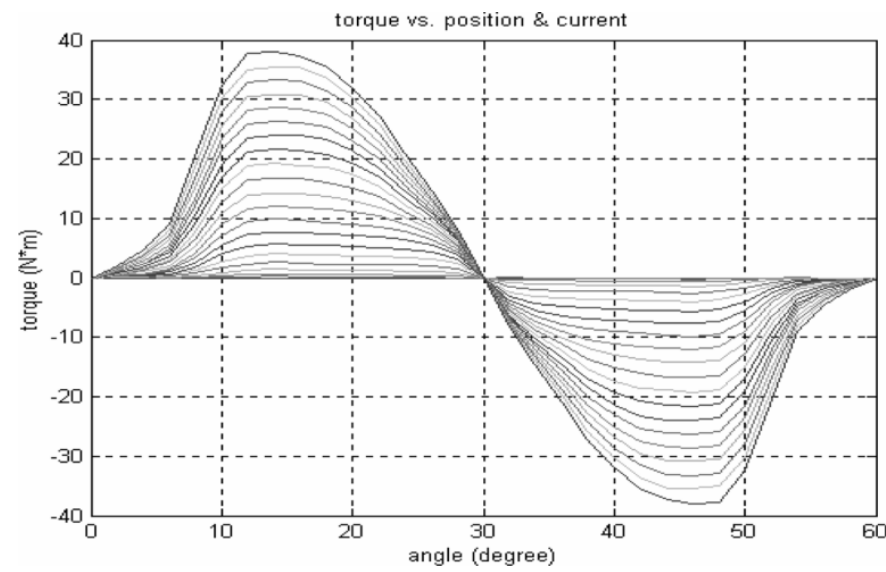

Fig. 7. Torque versus rotor position and phase current.
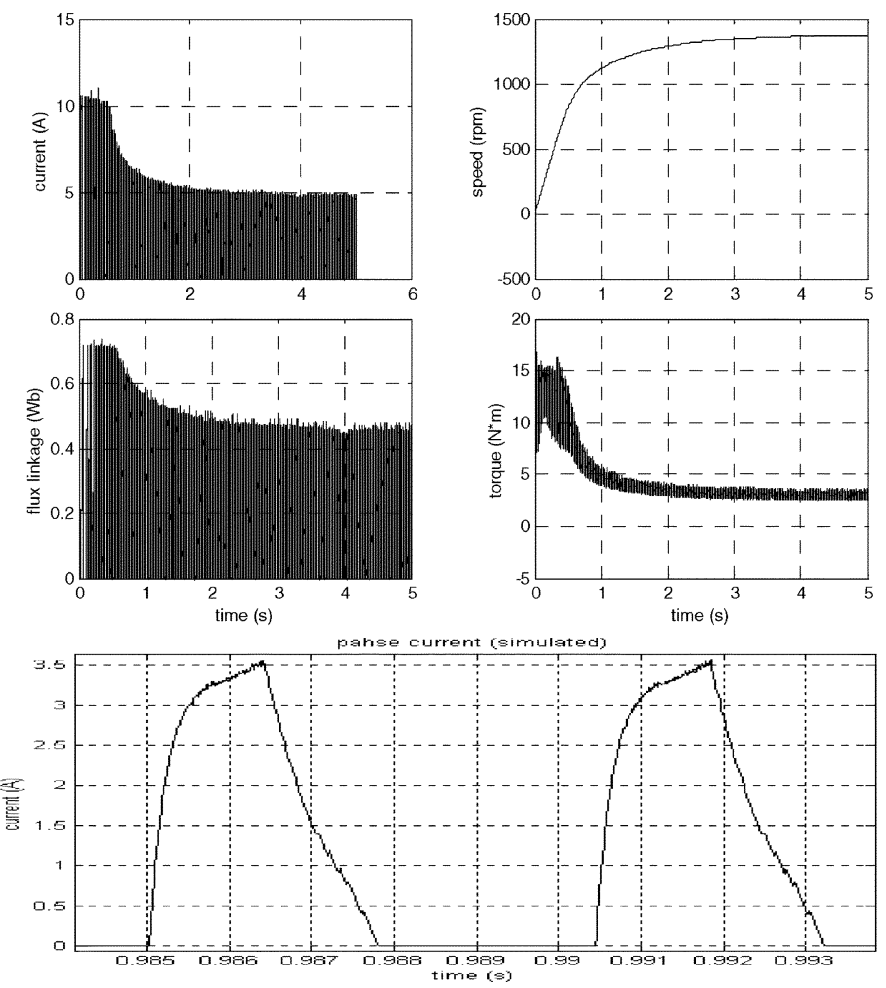

Fig. 8. Simulated transient phase current, rotor speed, flux linkage, and torque (accelerating).

mental tests. Again, the data used in this paper are measured from experimental tests, which are shown in Fig. 7.

Fig. 8 shows the simulated transient results of phase current, flux linkage, speed, and total torque. It is for operation at a speed of $1320 \mathrm{r} / \mathrm{min}$, with turn-on angle at $7^{\circ}$ and turn-off angle at $22.5^{\circ}$.

\section{Braking and Sudden Change of Torque Operation}

In industrial applications, SRMs do not always run at constant speed. Thus, it is necessary to analyze SRM operations under the condition of sudden change of torque/speed and even the operating status when changing from motoring to generating/braking.

The simulation model shown in Fig. 5 is good for simulating the SRM's startup from zero to full speed, then remaining at that constant speed. By adding two "switches," one called a "Direc- 


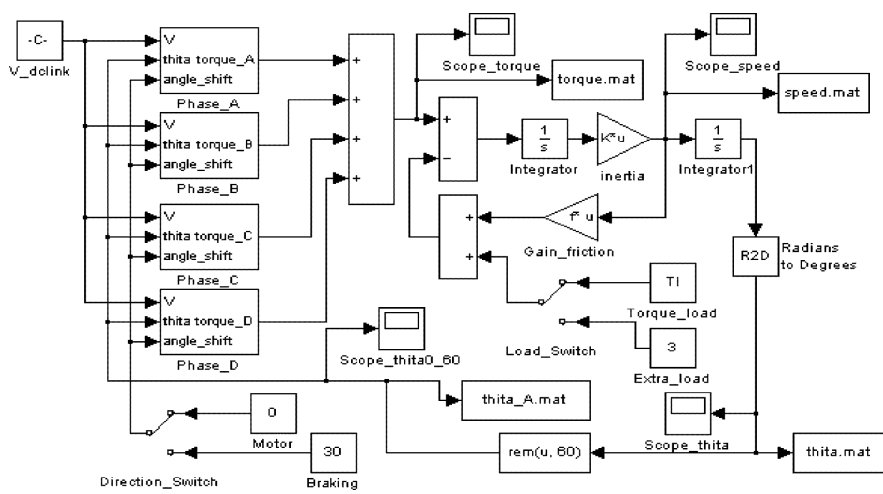

Fig. 9. Simulation model for sudden load change and braking operations.
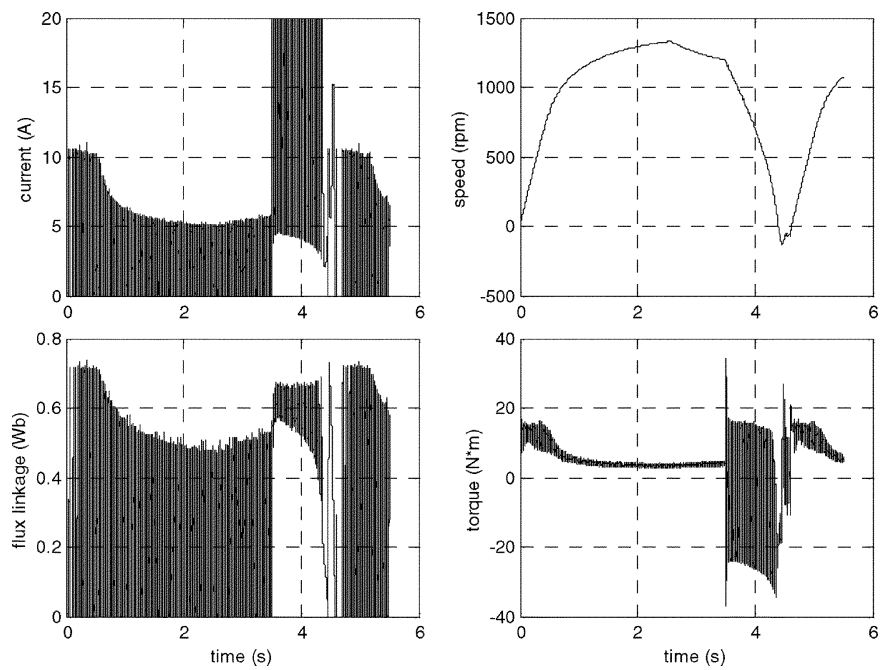

Fig. 10. Simulation results of phase current, rotor speed, flux linkage, and torque under different operating conditions: accelerating, sudden change of load, and braking.

tion switch," and the other called an "Extra load switch," the model will be able to simulate the operation with a change of load and braking. This new model is shown in Fig. 9.

The SRM can be easily operated with regenerative braking, when the turn-on angle $\theta_{\text {on }}$ is increased to make most of the phase current appear in the $\partial L / \partial \theta<0$ area. It is still one of the Angular Position Control (APC) modes. During braking, the direction of electromagnetic torque is opposite to the rotor rotation. The mechanical energy in the rotor is transformed to electrical energy, which will be fed back to the power source through power electronics, or dissipated in a resistor.

Fig. 10 shows the simulation results of phase current, rotor speed, flux linkage, and torque under different operating conditions: startup, sudden change of load, and braking. The simulation model shown in Fig. 9 is capable of simulating all of these operations.

The simulation consists of the motor starting up from 0 to $2.57 \mathrm{~s}$, then an additional $3-\mathrm{N} \cdot \mathrm{m}$ torque is added (the turn-on and turn-off angles are kept the same) from 2.57 to $3.5 \mathrm{~s}$. At $3.5 \mathrm{~s}$, the turn-on and turn-off angles are shifted by $30^{\circ}$ so that the motor is operating in the braking condition, until the speed reduces to be $0 \mathrm{r} / \mathrm{min}$. Finally, at $4.60 \mathrm{~s}$, the SRM is returned to motoring operation and back to startup.
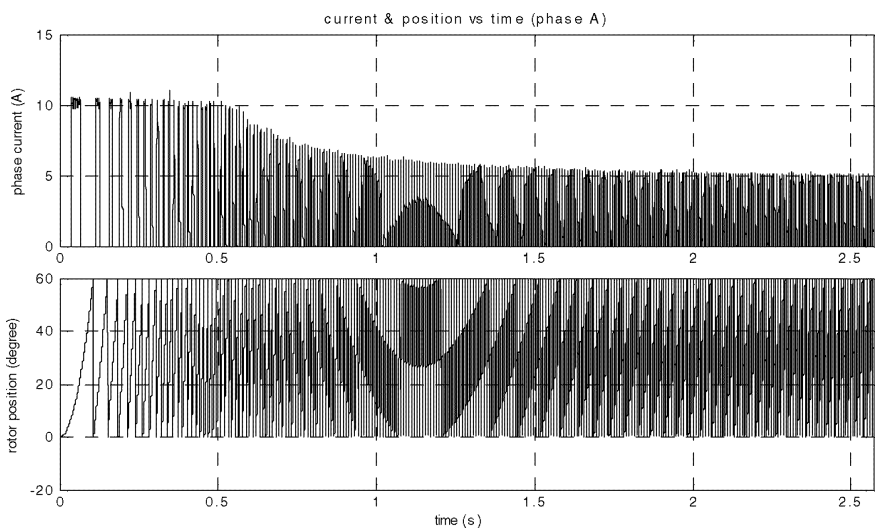

Fig. 11. Simulated phase current and rotor position (startup).

\section{RADIAL FORCES DURING TRANSIENT OPERATION}

As long as the current waveform is known, the transient force can be calculated from the lookup table. Fig. 11 shows the simulated phase current and rotor position. Notice that the rotor position is limited to be from $0^{\circ}$ to $60^{\circ}$, which is required for the radial force calculations.

Fig. 12 shows the calculated radial force (normal force) from lookup table technique, and its fast Fouriert transform (FFT). This radial force will be used later in the simulation model to predict the transient stator acceleration.

Fig. 13 shows the radial force and its FFT, using the same technique as described above. Compared with Fig. 12, which shows the radial force and its FFT during motor acceleration, the radial force shown in Fig. 13 is much more complicated, due to the change in different operating conditions. The FFT results show that there are higher levels of harmonics in the radial force in addition to new force harmonics when the operating conditions are changing, which means there are more opportunities to excite the resonant frequency of the motor stator.

The current waveform can also be obtained from experiments. Fig. 14 shows the recorded phase current waveform of the SRM at $1450 \mathrm{r} / \mathrm{min}$ (no load). With the known turn-on and turn-off angles, this current waveform is then used in the previous lookup table to calculate the normal force acting on the stator poles, as shown in Fig. 15.

An FFT operation is carried out for the above normal force as shown in Fig. 16. It has a dc component, fundamental, and harmonics. The normal force magnitudes of all the harmonics are shown in this figure together with the frequencies. This result can then be used as input in the simulation model described in the next section; thus, the output will be the simulated acceleration response.

\section{VIBRATION PREDICTION}

From a vibration point of view, the SRM is a complicated Multi-Degree of Freedom (MDOF) system. However it can be represented as the linear superposition of a finite number of Single-Degree of Freedom (SDOF) systems, which can be modeled as a viscously damped spring-mass system. The transient equation of motion can be obtained using Newton's law

$$
m \ddot{x}+c \dot{x}+k x=F(t)
$$



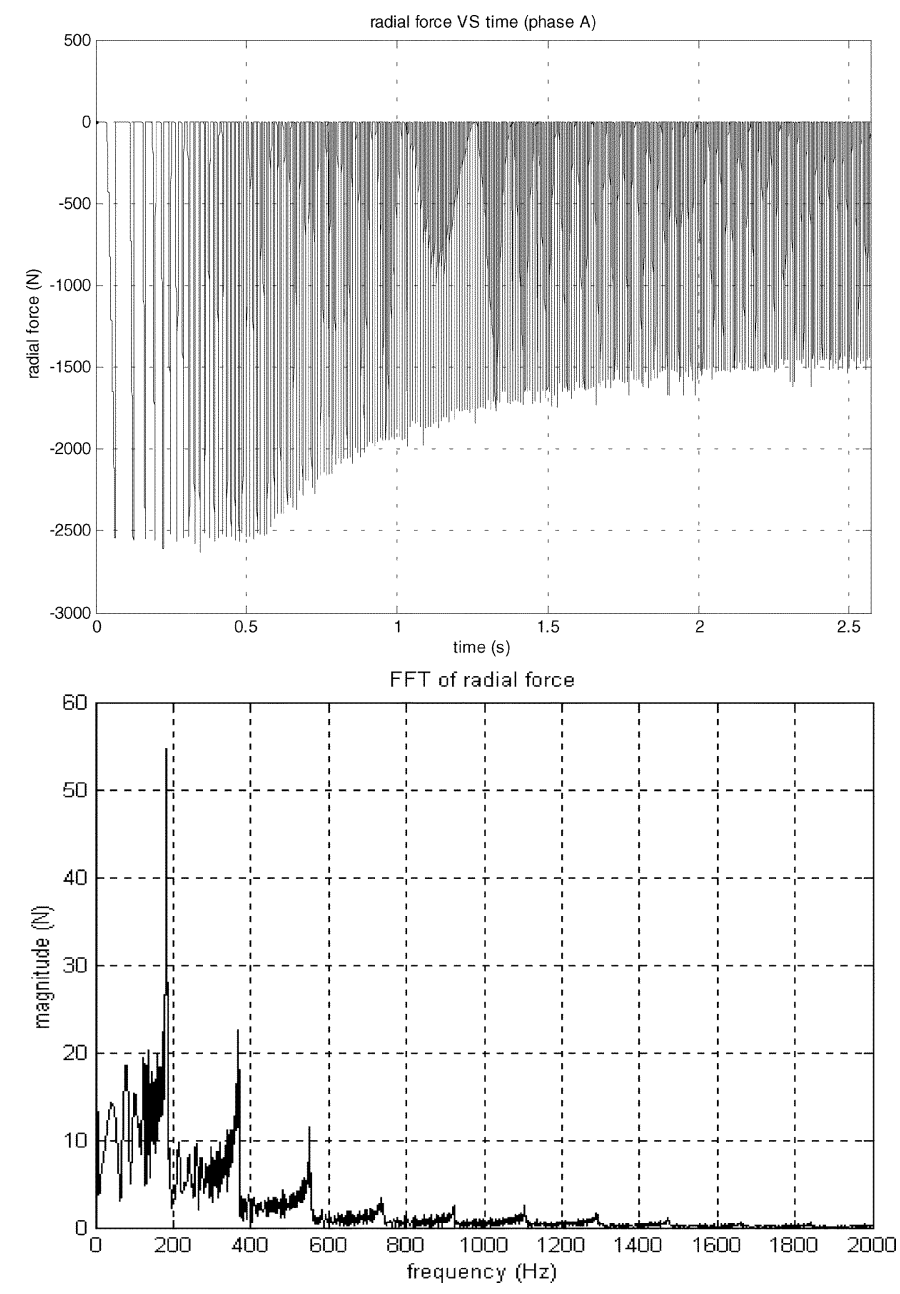

Fig. 12. Simulated radial force and its FFT (startup).

where $m$ is mass, $c$ is damping coefficient, $k$ is spring constant, and $x$ is displacement. Those parameters can be obtained by transfer function identification with a series of experiments [8]. The solution of (4) is the transient vibration, including displacement response, velocity response, and acceleration response.

Fig. 17 shows the simulation block of the transient vibration in the SRM. The normal force is calculated from the lookup table, using phase current results from the simulation described in the previous section. Fig. 18 shows the acceleration response under constant speed. Fig. 19 shows the simulated stator vibration and speed change during transient operation. Fig. 20 is the FFT analysis. Fig. 21 shows the three-dimensional (3-D) view of acceleration spectra during different operations under different speeds.

It is very clear that there are abundant harmonics of frequency during transients, which means it is easier to excite resonances.

\section{EXPERIMENT VALIDATION}

An 8/6-pole 4-kW SRM is driven by the classical converter for the experiment. A resistor is connected to the converter in parallel to provide energy dissipation during generating/braking operation. A dc generator with resistance load is connected with
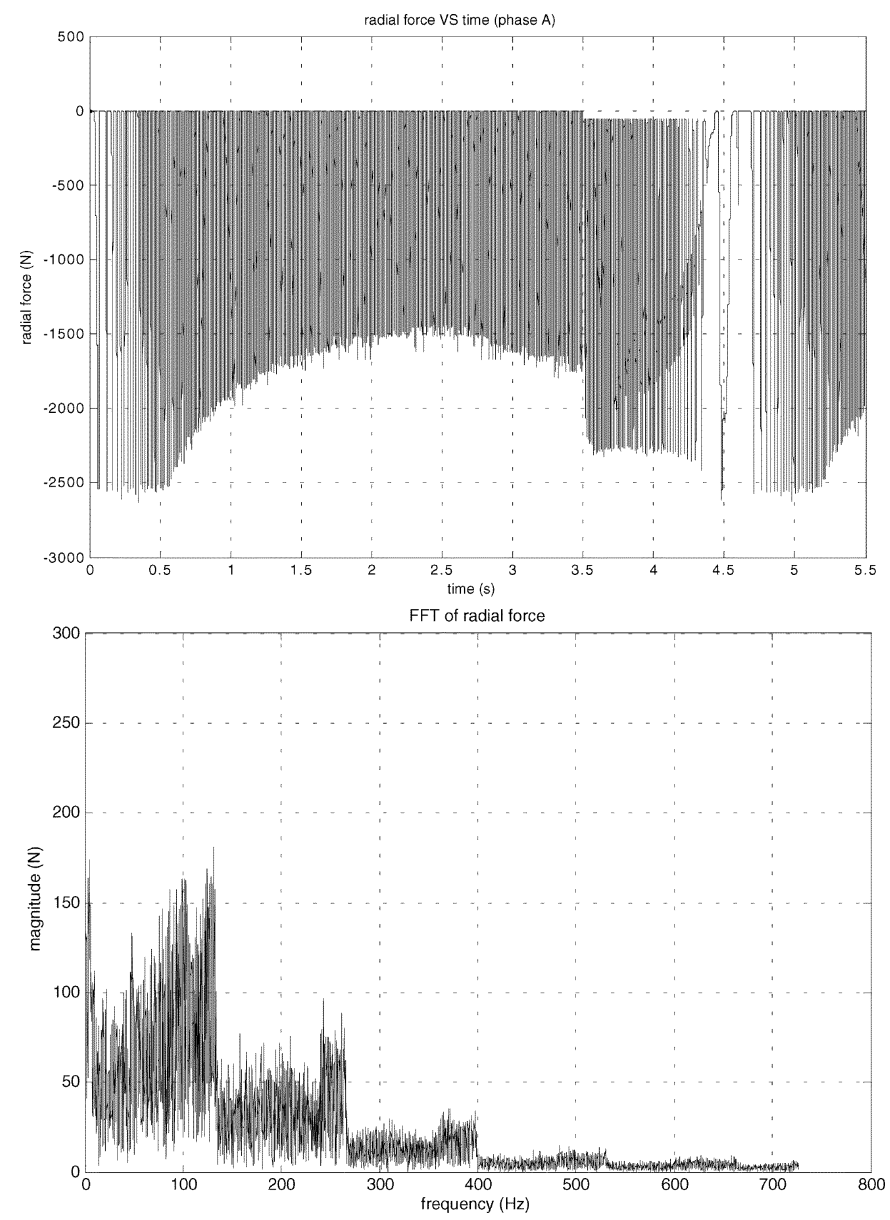

Fig. 13. Simulated radial force and its FFT (startup, sudden change of load, and braking).

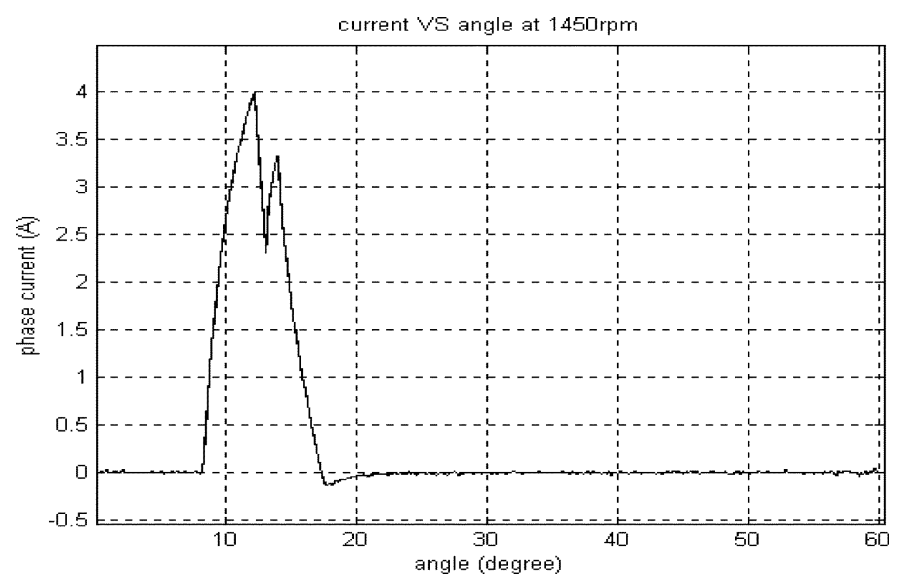

Fig. 14. Measured SRM phase current at $1450 \mathrm{r} / \mathrm{min}$.

the tested SRM as the load. dSPACE is used as the controller of the converter, which has the functions of DSP and AD/DA, and can be run under the environment of Matlab/Simulink.

The transient stator vibrations and phase currents are measured, as shown in Fig. 22. Fig. 22(a) shows the measured transient stator acceleration during startup, Fig. 22(b) is the FFT of the vibration, and Fig. 22(c) is the phase current. The measured 


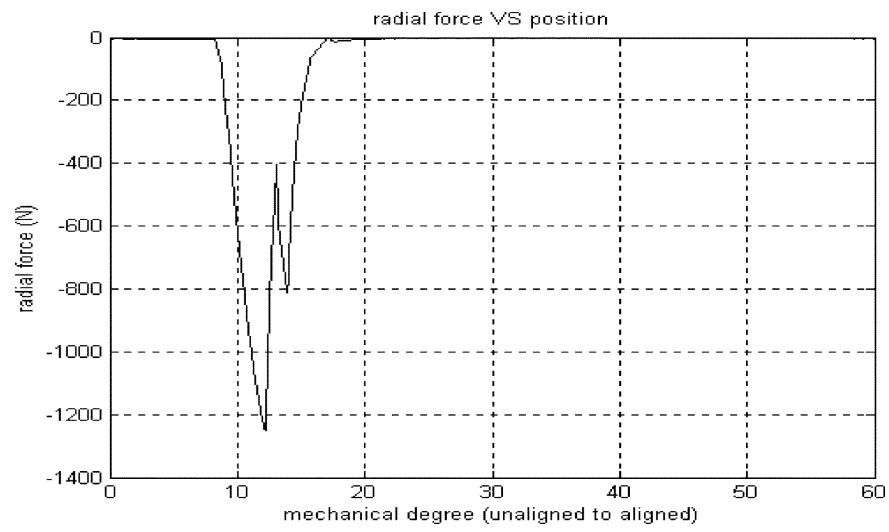

Fig. 15. Normal force calculated from lookup table.

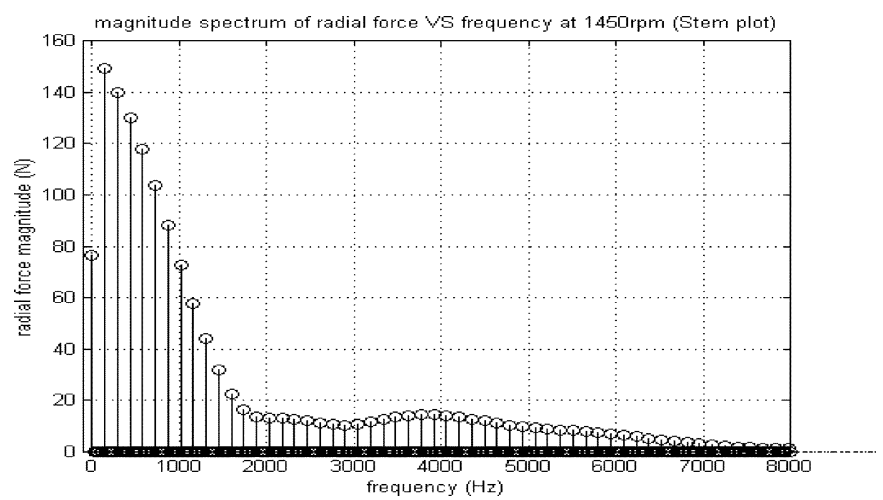

Fig. 16. FFT analysis results of normal force.

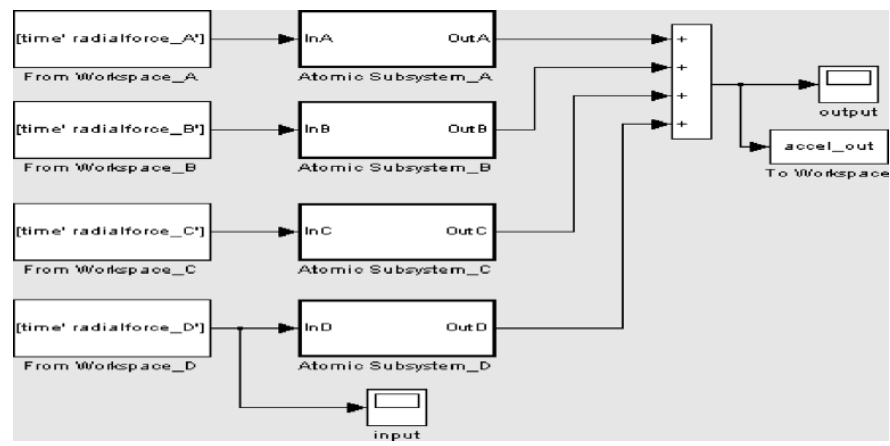

Fig. 17. Transient vibration simulation from normal force to stator acceleration.

acceleration and phase current are close enough to the simulated results, especially when the SRM reaches steady state.

Fig. 23 shows transient stator vibration and its FFT during load change. It can be seen that, as load increases, the vibration decreases. This is because the motor speed decreases with increase in load when turn-on and turn-off angles are kept unchangeable.

Fig. 24 shows the transient stator vibration and its FFT during braking operation. At this operating status, the stored kinetic energy is converted into electric energy and dissipated in the resistor, and the electromagnetic torque is negative. Thus, the vibration decreases with a decrease in speed. When speed falls to zero, the motor will be restarted in the opposite direction.

It should be emphasized that, although the vibrations during startup and braking do not significantly change compared with
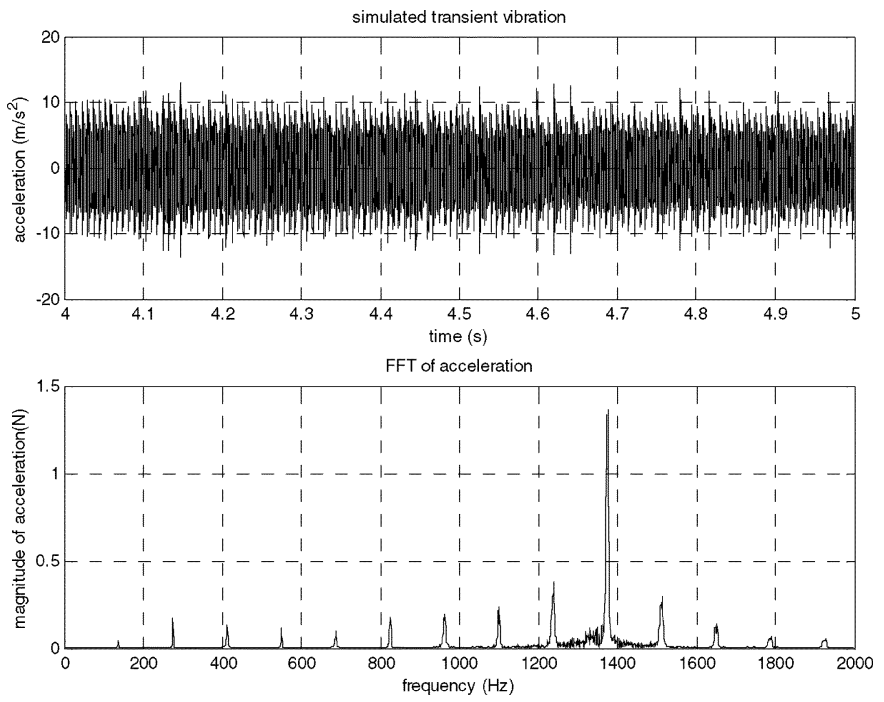

Fig. 18. Acceleration response in time and frequency domain under 1320 $\mathrm{r} / \mathrm{min}$.
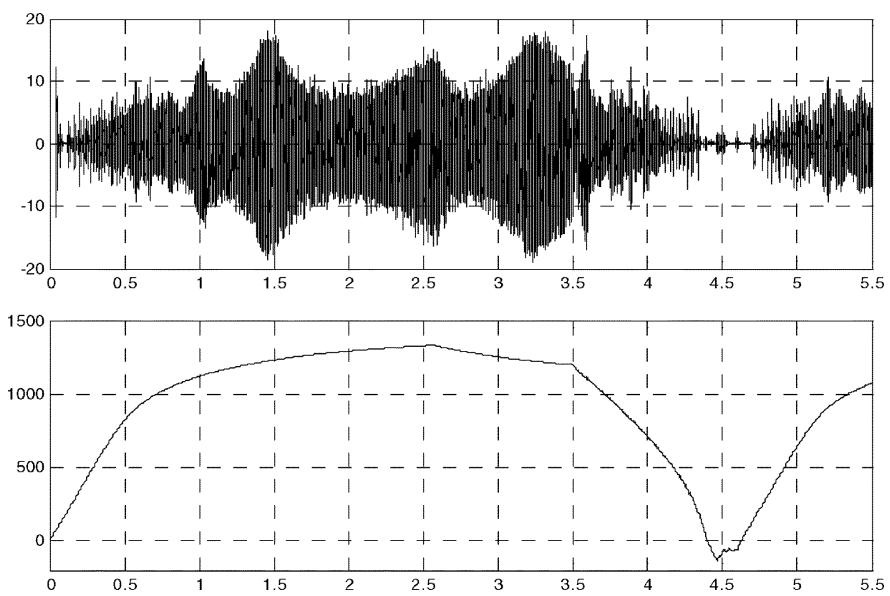

Fig. 19. Simulated vibration and speed change.

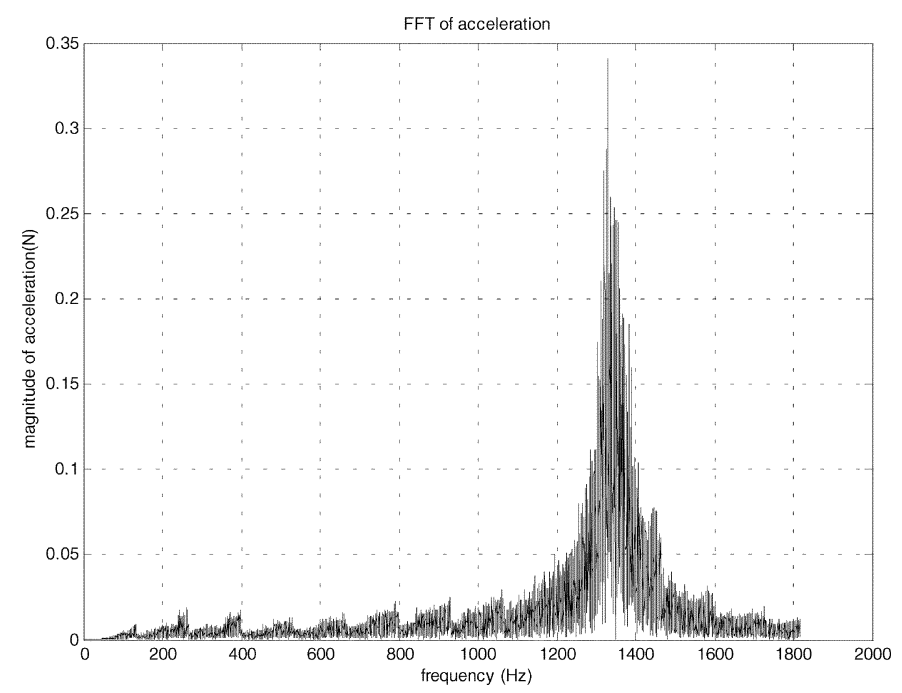

Fig. 20. FFT analysis of transient operation.

constant operation in this experiment, there exist more cases to excite resonance during these operations since there are more harmonics of the exciting force. The FFT analysis in Fig. 23 


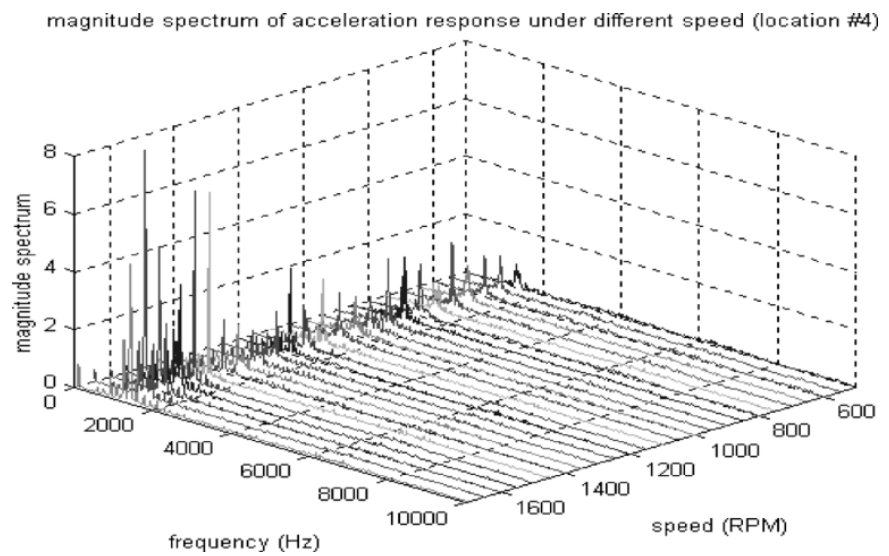

Fig. 21. 3-D view of acceleration spectra under different speeds.
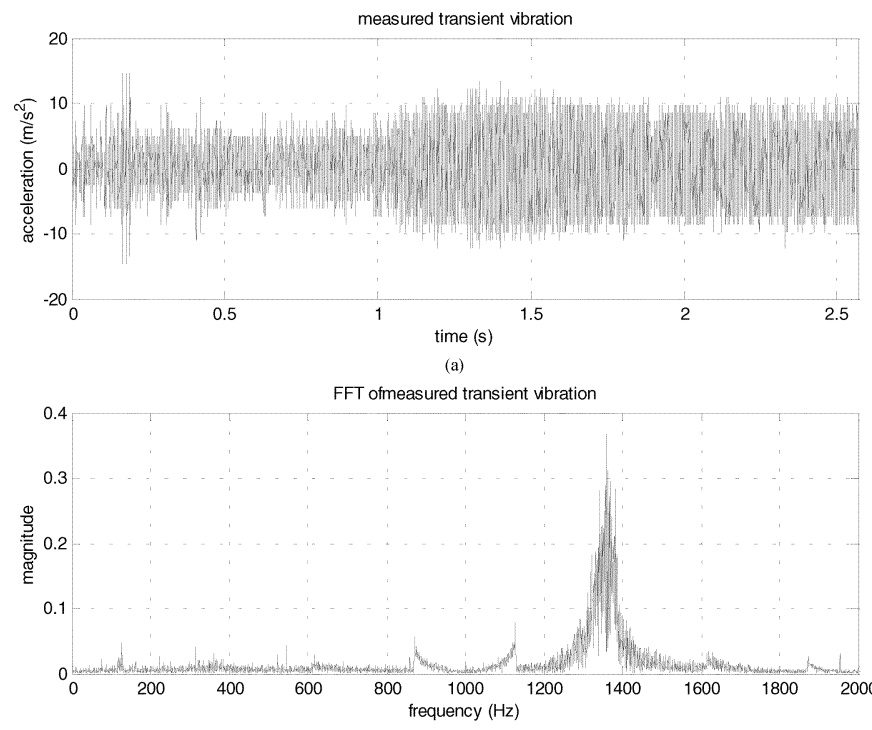

(b)

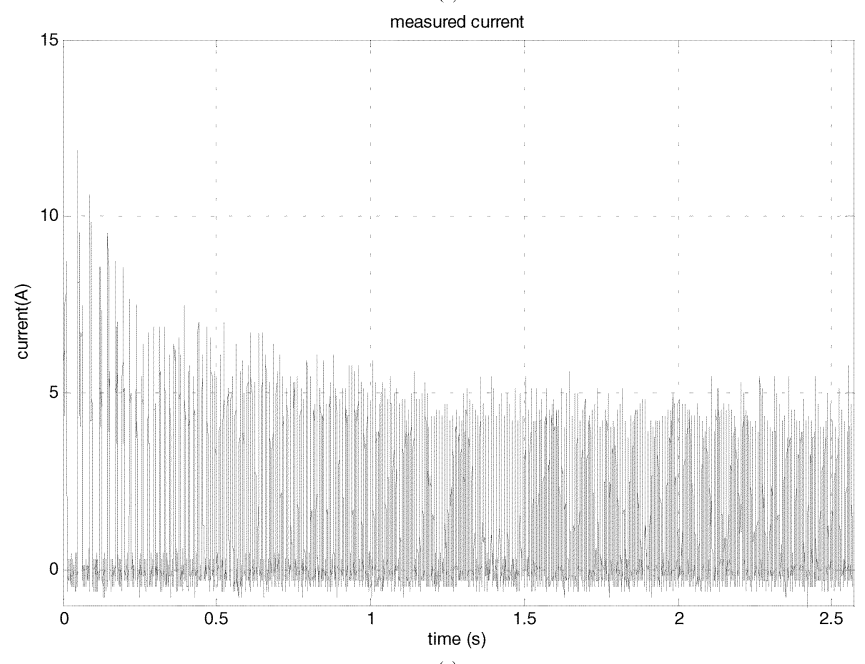

Fig. 22. Measured transient stator vibration and phase current.

shows that the maximum acceleration response is around 1380 $\mathrm{Hz}$, which is the natural resonant frequency of this motor.
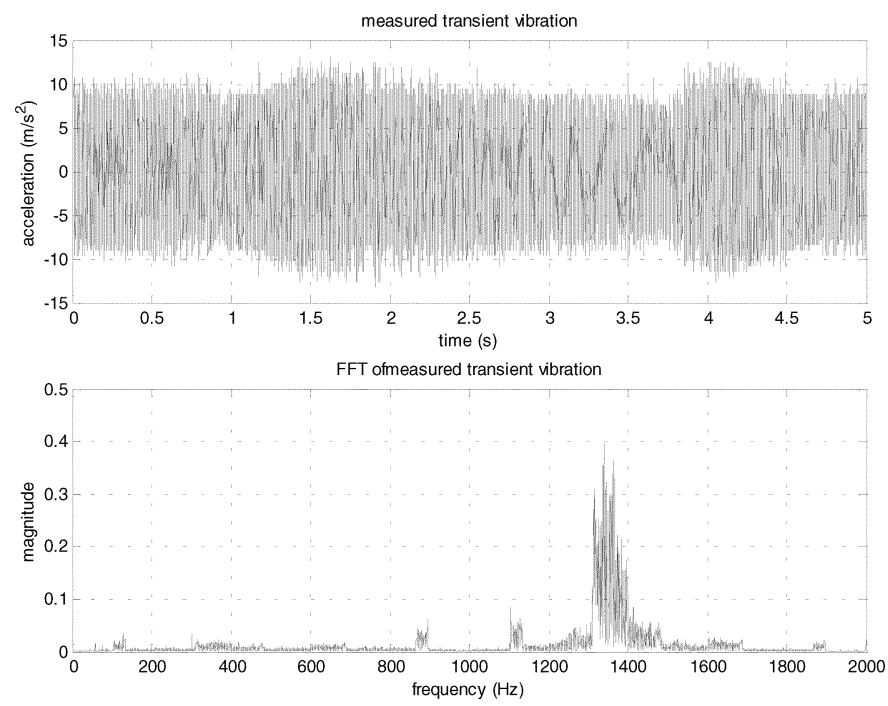

Fig. 23. Measured transient stator vibration and FFT during load change.
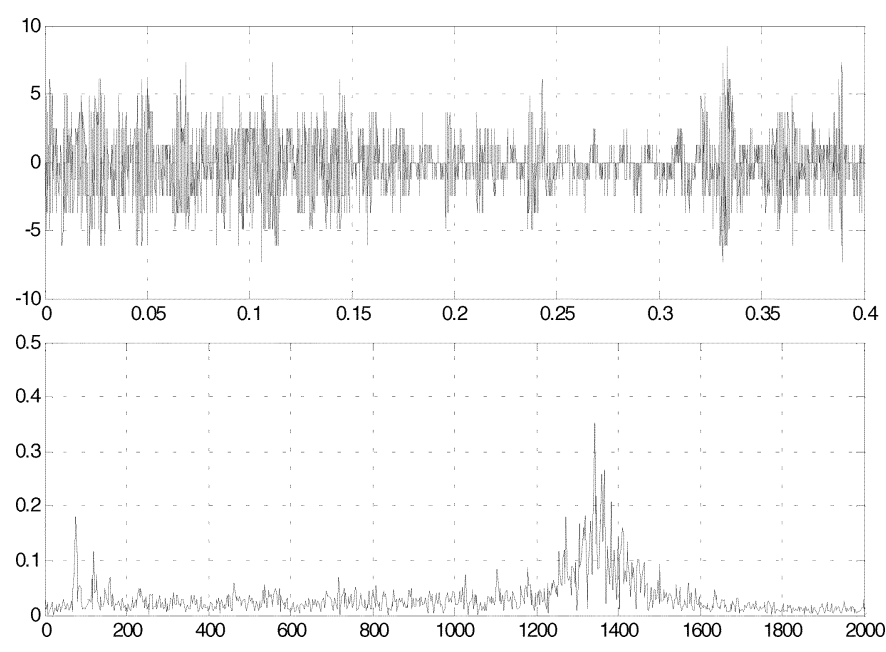

Fig. 24. Measured transient stator vibration and FFT during braking.

\section{CONCLUSION}

The vibration prediction model developed in this paper is built based on the detailed normal force versus phase current and rotor position lookup table using finite-element calculations It is useful and practical, and is verified by the running motor test, which shows acceptable accuracy. The results reveal that there are abundant harmonics of transient force during operation change, and that the resonant vibration can be excited. This program now allows the possibility of using the simulation model to improve design of SRMs from a vibration and acoustic noise point of view.

It is well known that the natural frequency of the motor should be designed as high as possible. However, there are several limitations on the mechanical design, such as power ratings, dimensions, materials, mounting requirements, etc. This paper presents an effective way to design an SRM to avoid resonant modes. For example, if a motor is designed to run primarily in the transient (startup and braking), the vibration can be simulated using the model in this paper and, hence, an optimal mechanical design can be achieved to avoid excitation of the resonant frequency. 


\section{ACKNOWLEDGMENT}

The authors acknowledge the support of Delphi Research Labs, Shelby Township, MI.

\section{REFERENCES}

[1] D. E. Cameron, J. H. Lang, and S. D. Umans, "The origin and reduction of acoustic noise in doubly salient variable-reluctance motors," IEEE Trans. Ind. Appl., vol. 28, no. 6, pp. 1250-1255, Nov./Dec. 1992.

[2] W. Cai, P. Pillay, Z. Tang, and A. Omekanda, "Vibration measurements in the switched reluctance motor," in Conf. Rec. IEEE-IAS Аnnu. Meeting, vol. 1, Chicago, IL, 2001, pp. 11-17.

[3] P. Pillay and W. Cai, "An investigation into vibration in switched reluctance motors," IEEE Trans. Ind. Appl., vol. 35, no. 3, pp. 589-596, May/Jun. 1999.

[4] W. Cai, P. Pillay, and A. Omekanda, "An analytical model to predict the modal frequencies of switched reluctance motors," in Proc. IEEE IEMDC, Boston, MA, Jun. 2001, pp. 203-207.

[5] P. J. Lawrenson, J. M. Stephenson, P. T. Blenkinson, J. Corda, and N. N. Fulton, "Variable-speed switched reluctance motors," Proc. Inst. Elect. Eng., pt. B, vol. 127, no. 4, pp. 253-265, Jul. 1980.

[6] G. Franceschini, S. Pirani, M. Rinaldi, and C. Tassoni, "Spice-assisted simulation of controlled electric drives: An application to switched reluctance drives," IEEE Trans. Ind. Appl., vol. 27, no. 6, pp. 1103-1110, Nov./Dec. 1991

[7] F. Soares and P. J. Costa Branco, "Simulation of a 6/4 switched reluctance motor based on Matlab/Simulink environment," IEEE Trans.

[8] Z. Tang, P. Pillay, and A. Omekanda, "Vibration prediction in switched reluctance motors with transfer function identification from Shaker and Force Hammer tests," IEEE Trans. Ind. Appl., vol. 39, no. 4, pp. 978-985, Jul./Aug. 2003. Aerosp. Electron. Syst., vol. 37, no. 3, pp. 989-1009, Jul. 2001.

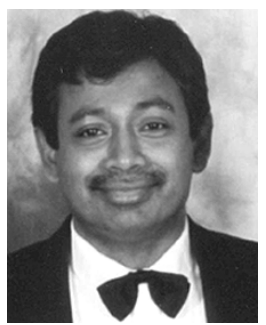

Pragasen Pillay (S'84-M'87-SM'92-F'05) received the Bachelor's degree from the University of Durban-Westville, Durban, South Africa, in 1981, the Master's degree from the University of Natal, Durban, South Africa, in 1983, and the Ph.D. degree from Virginia Polytechnic Institute and State University, Blacksburg, in 1987.

From January 1988 to August 1990, he was with the University of Newcastle-upon-Tyne, U.K. From August 1990 to August 1995, he was with the University of New Orleans. Currently, he is with Clarkson University, Potsdam, NY, where he is a Professor in the Department of Electrical and Computer Engineering and holds the Jean Newell Distinguished Professorship in Engineering. He is also an Adjunct Professor at the University of Cape Town, Cape Town, South Africa. His research and teaching interests are in modeling, design, and control of electric motors and drives for industrial and alternate energy applications.

Dr. Pillay is a member of the IEEE Power Engineering, IEEE Industry Applications (IAS), IEEE Industrial Electronics, and IEEE Power Electronics Societies. He is a member of the Electric Machines Committee and Past Chairman of the Industrial Drives Committee of the IAS and Past Chairman of the Induction Machinery Subcommittee of the IEEE Power Engineering Society. He currently chairs the Awards Co mmittee of the IAS Industrial Power Conversion Department. He has organized and taught short courses in electric drives at IAS Annual Meetings. He is a Fellow of the Institution of Electrical Engineers, U.K., and a Chartered Electrical Engineer in the U.K. He is also a Member of the Academy of Science of South Africa. He was also a recipient of a Fulbright Scholarship.

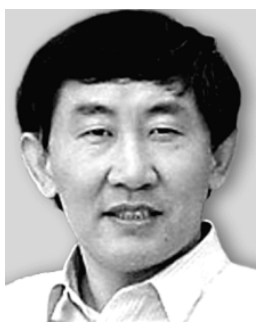

Yicheng Chen received the M.S. degree from Shenyang University of Technology, Shenyang, China, in 1984, and the Ph.D. degree from Clarkson University, Potsdam, NY, in 2004, both in electrical engineering.

His research and working experience includes electrical machine design and motor drives. He was a Professor of Electrical Engineering at Shenyang University of Technology. He is currently a Senior Commissioning Engineer with Siemens Energy and Automation, Inc., Alpharetta, GA.

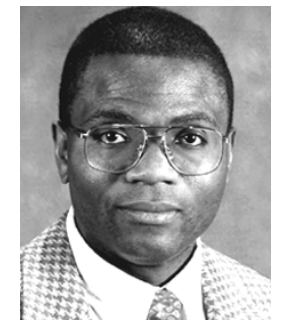

Avoki M. Omekanda (M'95-SM'97) received the bachelor's degree in physics from Mohammed V University, Rabat, Morocco, in 1984, and the Engineer and $\mathrm{Ph} . \mathrm{D}$. degrees in electrical engineering from the Faculté Polytechnique de Mons, Mons, Belgium, in 1987 and 1993, respectively.

Following the receipt of the Engineer's diploma, he worked for A.C.E.C Corporation, Charleroi, Belgium. In January 1990, he joined the Faculté Polytechnique de Mons as a Research Engineer. His research interests included computer-aided design for B.S. degree in electrical engineering from Harbin Institute of Technology, Harbin, China, in 1994 the M.S. degree from Beijing Institute of Control Devices, Beijing, China, in 1997, and the Ph.D. degree from Clarkson University, Potsdam, NY, 2002.

Following receipt of the M.S. degree, he spent 2 $1 / 2$ additional years at Beijing Institute of Control Devices, developing gyroscope motor and control systems for various navigation platforms. In September 2002, he joined Stryker Instruments, Kalamazoo, MI, as a Senior Design Engineer in the Powertools Product Platform Research and Development Group. His research interests include design, control, and modeling of electrical machines and drives, numerical computation of electromagnetic fields and mechanical structures, and vibration and noise of electrical machines. switched reluctance machines and magnetic field computation using numerical methods. After receiving the Ph.D. degree, he was an Assistant Professor in the Electrical Engineering Department, Faculté Polytechnique de Mons, for two years. In June 1995, he joined the General Motors Research and Development Center, Warren, MI, as a Senior Research Engineer. In 1999, he became part of Delphi Research Labs, Shelby Township, MI, where he is currently a Staff Research Engineer. His research interests include design, analysis, and control of electric machines, in particular, switched reluctance, for automotive applications. He is the holder of seven U.S. patents, with 13 pending, and six foreign patents.

Dr. Omekanda is a Member of the Association des Ingénieurs de Mons (Belgium) and Société des Electriciens et des Electroniciens (France). 